\title{
Hubungan Antara Pola Tutupan Lahan Terbangun Dan Laju Infiltrasi Air Hujan
}

\author{
Krisantos R. BELA ${ }^{1}$ Engelbertha N. BRIA SERAN ${ }^{2} \cdot$ Mauritius I.R. NAIKOFI $^{3}$. \\ Don Gaspar Noesaku DA COSTA ${ }^{4}$ \\ ${ }^{1}$ Program Studi Teknik Sipil, Fakultas Teknik, Universitas Katolik Widya Mandira, email: \\ krisantos_bela@yahoo.com \\ ${ }^{2}$ Program Studi Teknik Sipil, Fakultas Teknik, Universitas Katolik Widya Mandira, email: \\ engelberthabs@gmail.com \\ ${ }^{3}$ Program Studi Teknik Sipil, Fakultas Teknik, Universitas Katolik Widya Mandira, email: \\ mauritiusnaikofi@yahoo.co.id \\ ${ }^{4}$ Program Studi Teknik Sipil, Fakultas Teknik, Universitas Katolik Widya Mandira, email: \\ dnoesaku@gmail.com
}

\begin{abstract}
Kupang City is an area in Indonesia which has a relatively low number of rainy days. This causes the supply of clean water or drinking water in Kupang City to decrease. The high infiltration rate not only increases the amount of water stored in the soil, but also reduces flooding and erosion caused by run off. This study aims to model the relationship between infiltration and discharge capability for each type of samples land by using linear regression method. For this reason, a water absorption test was conducted on the built up area based on the infiltration rate. The results of experiments and calculations using linear regression shown that area often received heavy load such as vehichles had lower infiltration rate leading to slow inundation height decrease. While areas rarely received heavy load had higher infiltration rate. Even though the difference is only around 2-3 cm / 5 minutes, it indicates that the availability of open areas is still needed to support the implementation of the zero run-off model in urban built areas.
\end{abstract}

Keywords: infiltration rate, linear regression, built up area

\section{Pendahuluan}

Perkembangan fisik perkotaan mengakibatkan terjadinya perubahan penggunaan lahan dari lahan terbuka menjadi lahan terbangun (Utaya, 2008). Pembangunan lahan suatu kawasan mencerminkan fungsi ruang hidrogeologi kawasan tersebut. Banyaknya konversi lahan akan memperluas permukaan kedap air sehingga menyebabkan berkurangnya infiltrasi, menurunnya pasokan air tanah dan meningkatnya limpasan permukaan. Perubahan ini pada akhirnya akan mempengaruhi sistem neraca air, sehingga fungsi hidrogeologis akan bergeser seiring ruang dan waktu (Maria dan Lestiana, 2014).

Secara geografis kota Kupang terletak pada $10^{\circ} 36^{\prime} 14^{\prime \prime}-10^{\circ} 39^{\prime} 58^{\prime \prime}$ LS dan $123^{\circ} 32^{\prime} 23^{\prime \prime}-$ $123^{\circ} 37^{\prime} 01^{\prime}$ 'BT. Posisi geografis ini menyebabkan Kota Kupang memiliki pola musim hujan monsunal dengan musim kemarau yang relatif panjang dan musim hujan yang relatif pendek. Kota Kupang juga merupakan wilayah di Indonesia yang memiliki jumlah hari hujan yang tergolong rendah, yaitu sekitar 115 hari pertahun, didominasi oleh hujan lebat yang terjadi tiba-tiba atau biasa dikenal dengan istilah showers (Wardhana, 2015). Hal ini menyebabkan penyediaan air bersih ataupun air minum di Kota Kupang semakin berkurang (krisis air

*penulis korespondensi 
bersih). Kondisi ini terjadi tidak hanya di daerah perkotaan, tetapi juga turut dirasakan oleh warga pedesaan.

Penyebab rendahnya capaian air minum layak di Indonesia meliputi faktor non teknis dan teknis (Wardiha dkk, 2013). Faktor non teknis misalnya kebiasaan atau adat masyarakat, keberterimaan masyarakat serta kontribusi masyarakat dalam peningkatan kualitas penyediaan air di lokasinya. Sedangkan faktor teknis misalnya debit sumber air, jarak sumber air ke permukiman, kondisi perpipaan, perubahan jenis tutupan lahan dari lahan terbuka ke lantai kedap air. Luapan air dari saluran drainase ke badan jalan maupun pekarangan dan lain sebagainya mengindikasikan bahwa volume limpasan air ke hilir kawasan sudah tidak mampu ditampung oleh kapasitas saluran drainase eksisting. Pelebaran dimensi saluran biasanya membutuhkan sumber daya (biaya konstruksi, biaya pembebasan lahan) yang tinggi sehingga pengelolaan limpasan air berbasis konservasi di hulu maupun sepanjang trase lintasan saluran drainase maupun jaringan jalan diperkirakan dapat meminimalkan debit limpasan ke hilir kawasan perkotaan.

Berdasarkan uraian permasalahan tersebut, maka maksud penelitian ini adalah untuk mempertahankan keseimbangan hidrologis, terutama pada bagian kawasan perkotaan (lahan terbangun), berbasis konservasi untuk selanjutnya merekomendasikan strategi serta teknik pengelolaan sumber daya air berbasis konservasi di lahan-lahan terbangun perkotaan tersebut. Dengan demikian tujuan penelitian ini adalah untuk mengidentifikasi kemampuan (daya resap air) di bagian kawasan perkotaan Kupang, khususnya di lahan-lahan terbangun dengan potensi genangan yang tinggi dan/atau dengan tingkat penggunaan sumur bor yang tinggi. Selain itu, tujuan penelitian ini juga diarahkan untuk menentukan strategi dan teknik konservasi air dan/atau tanah yang sesuai dengan daya resap air (infiltrasi dan perkolasi) di bagian kawasan perkotaan tersebut. Diharapkan agar hasil studi/penelitian ini dapat dijadikan dasar penentuan kebijakan (strategi) dan teknik (cara/metode) pengelolaan sumber daya air berbasis konservasi air dan/atau lahan di bagian kawasan perkotaan dimaksud secara berkelanjutan.

\section{Tinjauan Pustaka}

Infiltrasi adalah aliran air ke dalam tanah melalui permukaan tanah. Di dalam tanah, air mengalir dalam arah lateral, sebagai aliran antara (interflow) yang menuju mata air, danau dan sungai; atau secara vertikal, yang dikenal dengan perkolasi (percolation) menuju air tanah (Muharomah, 2014). Laju infiltrasi yang tinggi tidak hanya meningkatkan jumlah air yang tersimpan dalam tanah untuk pertumbuhan tanaman, tetapi juga mengurangi banjir dan erosi yang disebabkan oleh run off (Hakim, 1986).

Gerak air di dalam tanah melalui pori-pori tanah dipengaruhi oleh gaya gravitasi dan gaya kapiler. Gaya gravitasi menyebabkan aliran selalu menuju ke tempat yang lebih rendah, sementara gaya kapiler menyebabkan air bergerak ke segala arah. Air kapiler selalu bergerak dari daerah basah menuju ke daerah yang lebih kering. Tanah kering mempunyai gaya kapiler lebih besar dibandingkan tanah basah (Muharomah, 2014). Gaya tersebut berkurang dengan bertambahnya kelembaban tanah. Selain itu, gaya kapiler bekerja lebih kuat pada tanah dengan butiran halus seperti lempung daripada tanah berbutir kasar seperti pasir. Apabila tanah kering, air terinfiltrasi melalui permukaan tanah karena pengaruh gaya gravitasi dan gaya kapiler pada seluruh permukaan. Setelah tanah menjadi basah, gerak kapiler berkurang karena berkurangnya gaya kapiler. Hal ini menyebabkan penurunan laju infiltrasi. Sementara aliran kapiler pada lapis permukaan berkurang, aliran karena pengaruh gaya gravitasi berlanjut mengisi pori-pori tanah. Dengan terisinya pori-pori tanah, laju infiltrasi berkurang 
secara berangsur-angsur sampai dicapai kondisi konstan, dimana laju infiltrasi sama dengan laju perkolasi melalui tanah (Muharomah, 2014).

Laju infiltrasi dipengaruhi oleh beberapa faktor, diantaranya yaitu kedalaman genangan dan tebal lapisan jenuh, kelembaban tanah, pemampatan butir tanah oleh hujan, penyumbatan oleh butiran halus, tanaman penutup, kondisi topografi, dan intensitas hujan (Muharomah, 2014). Semakin besar kemiringan lahan maka laju aliran permukaan akan semakin cepat, daya kikis dan daya angkut aliran permukaan makin cepat dan kuat. Oleh karena itu strategi konservasi tanah dan air pada lahan berlereng adalah memperlambat laju aliran permukaan dan memperpendek panjang lereng untuk memberikan kesempatan lebih lama pada air untuk meresap kedalam tanah (Kurnia dkk, 2004).

\section{Metodologi}

Data yang digunakan dalam penelitian ini adalah data primer yaitu data hasil penelitian di lapangan secara langsung, yang meliputi pendataan luasan, ketinggian dan durasi genangan di lahan yang sama dengan kondisi tanah yang berbeda pada tiap lahan sampel secara berturutturut selama 1 minggu.

Pengukuran kemampuan infiltrasi dan perkolasi air dilakukan dengan menuangkan sejumlah debit air dengan kecepatan tertentu (menggunakan truck tangki air) ke tiap jenis lahan terbangun tersebut dengan prosedur sebagai berikut:

a. Luas dan jenis tanah di lahan sampel diamati, dan diukur. Lahan sampel yang dipilih adalah lahan yang diperkirakan mampu menampung debit air sekitar $5 \mathrm{~m}^{3}$. Pertimbangannya adalah dengan volume air tersebut, ketinggian genangan air di lahan sampel dapat mencapai ketinggian genangan maksimum yang masih dapat diterima di bagian kawasan perkotaan yaitu $10-30 \mathrm{~cm}$.

b. Air tangki dituang seluruhnya secara perlahan-lahan ke lahan sampel guna pencatatan durasi, luasan dan ketinggian genangan di tiap lahan sampel. Untuk itu lahan sampel yang dipilih hendaknya yang memungkinkan terjadinya genangan air hingga sekitar $30 \mathrm{~cm}$ (lahan yang dibatasi secara fisik baik oleh pasangan pondasi maupun oleh jenis pembatas fisik lainnya.

c. Penuangan/pelimpasan air tangki di tiap lahan sampel tersebut dilakukan sebanyak 5 kali dengan tenggang waktu penuangan/pelimpasan adalah sekitar 1x24 jam. Asumsinya adalah setiap hari terjadi curah hujan di kawasan tersebut dengan intensitas yang tinggi dan bersifat konstan. Dengan metode tersebut, kemungkinan luapan air ke lahan pekarangan disekitarnya akibat ketidakmampuan lahan sampel dalam meresapkan air dapat diidentifikasi. Hasilnya dijadikan dasar penentuan luas lahan minimum yang perlu disediakan di tiap lahan terbangun untuk fungsi peresapan air.

Selanjutnya, dilakukan tahapan pemodelan hubungan antara kemampuan infiltrasi dan debit untuk tiap jenis lahan sampel menggunakan perhitungan (regresi).

\section{Analisis dan Pembahasan}

\section{Pemilihan Lokasi Uji Coba}

Secara spasial, lahan pekarangan perumahan / permukiman yang dijadikan lokasi studi ini terletak di Jalan Bumi I, Block III No. 24. Di sepanjang penggal jalan tersebut terdapat sejumlah kapling perumahan yang sebagian pekarangannya belum dilapisi dengan material kedap air. Namun demikian, lokasi studi terpilih diambil karena sejumlah pertimbangan yaitu: 
Pertama, kesesuaiannya dengan tujuan aplikasi model zero run-off dimana walaupun elevasi muka tanah pekarangan lebih rendah dari elevasi muka jalan, namun air limpasan permukaan dari badan jalan atau kapling tetangga tidak dapat masuk ke lahan pekarangan yang diamati karena dibatasi oleh pondasi pagar pekarangan. Dengan demikian, karakter tersebut cocok digunakan untuk penentuan luas area resapan minimum yang dibutuhkan agar model zero run-off dapat diterapkan pada lahan kapling tersebut.

Kedua, Kemungkinan limpasan air ke luar lahan kapling dimana Lahan kosong (area terbuka) yang tersedia terdapat di depan, samping dan belakang bangunan tempat tinggal, dimana tiap area tersebut disediakan untuk menampung air hujan yang jatuh dari tiap bagian atap dan/atau lahan terbuka. Dengan demikian, efektivitas luasan lahan yang disediakan tersebut dalam menampung dan meresapkan air hujan dapat diamati secara lebih seksama.

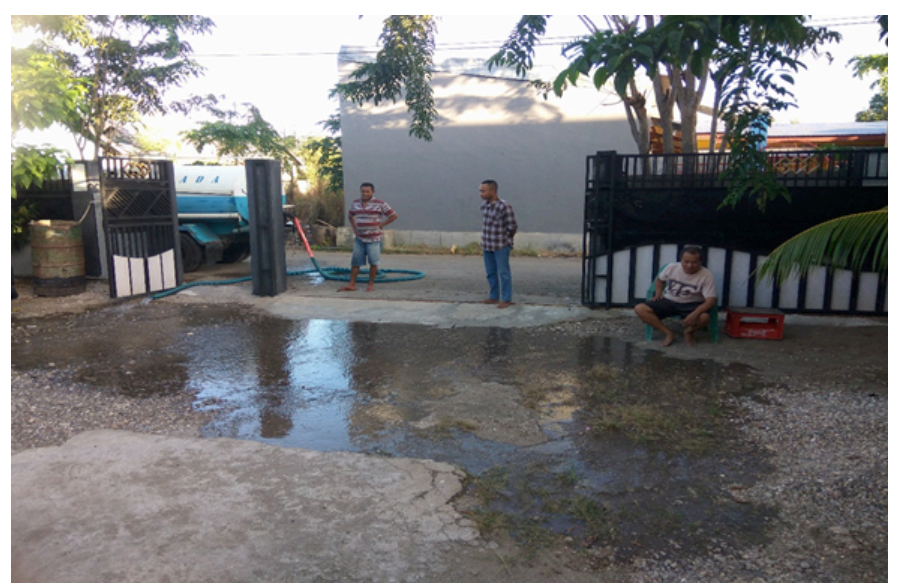

Gambar 1. Mekanisme penggenangan lahan

\section{Durasi Penggenangan}

Total air yang dilimpaskan ke halaman yang diamati adalah sekitar 5000 liter (seluruh air truck tanki). Agar dampak limpasan terhadap penggenangan lahan mendekati situasi curah hujan tertinggi di musim penghujan maka walaupun mesin pompa dihidupkan namun kecepatan mesin diatur pada posisi terendah sehingga kecepatan pengaliran air menyerupai pola pengalirannya secara gravitasi ( 3 hari pertama). Selanjutnya, ujicoba dilakukan dengan mengalirkan air secara gravitas (mesin pompa air tanki dimatikan, 2 hari terakhir). Model penggenangan yang kedua ini untuk menggambarkan/mengidentifikasi dampak dari durasi penggenangan yang lebih panjang. Selain itu, titik pengaliran diletakkan di bagian pekarangan tertinggi sehingga air dapat mengalir secara gravitasi ke bagian pengarangan lainnya seperti yang ditunjukan pada Gambar 1 .

\section{Ketinggian Genangan}

Terlepas dari perbedaan pola penggenangan tersebut, ketinggian genangan yang terjadi pada lahan pengamatan adalah berkisar antara $4-11 \mathrm{~cm}$ seperti yang ditunjukan pada Tabel $1 \mathrm{dan}$ Tabel 2. Perbedaan pola penggenangan berdampak pada durasi pelimpasan air yang pada gilirannya berdampak pada ketinggian genangan. Di dua hari terakhir, intensitas air yang dilimpaskan lebih kecil sehingga durasi pelimpasan menjadi lebih lama dan ketinggian genangan maksimumnya lebih rendah dari pola penggenangan yang pertama. Hal tersebut mungkin disebabkan karena sebagian air berhasil terserap oleh tanah karena tingginya porositas tanah 
Tabel 1. Pertambahan Ketinggian Genangan per 5 menit Peningkatan Durasi Penggenangan di Pojok Halaman

\begin{tabular}{|c|c|c|c|c|c|}
\hline \multirow{2}{*}{$\begin{array}{l}\text { Waktu } \\
\text { / } 5 \text { menit } \\
\text { (X) }\end{array}$} & \multicolumn{5}{|c|}{ KETINGGIAN GENANGAN (Y) DI POJOK HALAMAN (TANAH ASLI) } \\
\hline & $\begin{array}{c}\text { Jumat, } \\
3 \text { Mei'19 } \\
(\mathrm{cm})\end{array}$ & $\begin{array}{c}\text { Sabtu, } \\
4 \text { Mei'19 } \\
(\mathrm{cm})\end{array}$ & $\begin{array}{c}\text { Minggu, } \\
5 \text { Mei'19 } \\
(\mathrm{cm})\end{array}$ & $\begin{array}{c}\text { Senin, } \\
6 \text { Mei'19 } \\
(\mathrm{cm})\end{array}$ & $\begin{array}{c}\text { Selasa, } \\
7 \text { Mei'19 } \\
(\mathrm{cm})\end{array}$ \\
\hline $5 "$ & 6 & 6.2 & 6.3 & 6.5 & 7.9 \\
\hline $10 ”$ & 8 & 9 & 7.5 & 7.5 & 8.8 \\
\hline $15 ”$ & 9 & 10 & 9.5 & 8 & 9.5 \\
\hline $20 "$ & 9.2 & 10.2 & 11.2 & 8.8 & 10 \\
\hline $25^{\prime \prime}$ & & & & 9.2 & 10.3 \\
\hline $30 "$ & & & & 9.8 & 10.5 \\
\hline
\end{tabular}

Tabel 2. Pertambahan Ketinggian Genangan per 5 menit Peningkatan Durasi Penggenangan di Gerbang Akses

\begin{tabular}{|c|c|c|c|c|c|}
\hline \multirow{2}{*}{$\begin{array}{c}\text { Waktu } \\
\text { / } \begin{array}{c}\text { menit } \\
(\mathrm{X})\end{array}\end{array}$} & $\begin{array}{c}\text { Jumat, } \\
\text { 3 Mei'19 } \\
(\mathrm{cm})\end{array}$ & $\begin{array}{c}\text { Sabtu, } \\
4 \text { Mei'19 } \\
(\mathrm{cm})\end{array}$ & $\begin{array}{c}\text { Minggu, } \\
5 \text { Mei'19 } \\
(\mathrm{cm})\end{array}$ & $\begin{array}{c}\text { Senin, } \\
6 \text { Mei'19 } \\
(\mathrm{cm})\end{array}$ & $\begin{array}{c}\text { Selasa, } \\
\text { Mei'19 } \\
(\mathrm{cm})\end{array}$ \\
\hline $5 "$ & 4 & 4.3 & 4.4 & 4.5 & 6 \\
\hline $10 "$ & 6 & 7 & 5.5 & 5.5 & 7 \\
\hline $15 ”$ & 7 & 8 & 7.5 & 6.5 & 7.5 \\
\hline $20 ”$ & 7.2 & 8.2 & 9.2 & 7.2 & 7.8 \\
\hline $25 ”$ & & & & 8 & 8.6 \\
\hline $30 "$ & & & & 8.8 & 9 \\
\hline
\end{tabular}

\section{Laju Infiltrasi}

Pengukuran kecepatan penurunan ketinggian genangan dilakukan pada 3 titik pengamatan seperti yang ditunjukan pada Gambar 2 sehingga diperoleh data penurunan ketinggian seperti yang dicantumkan pada Tabel 3 dan Tabel 4.
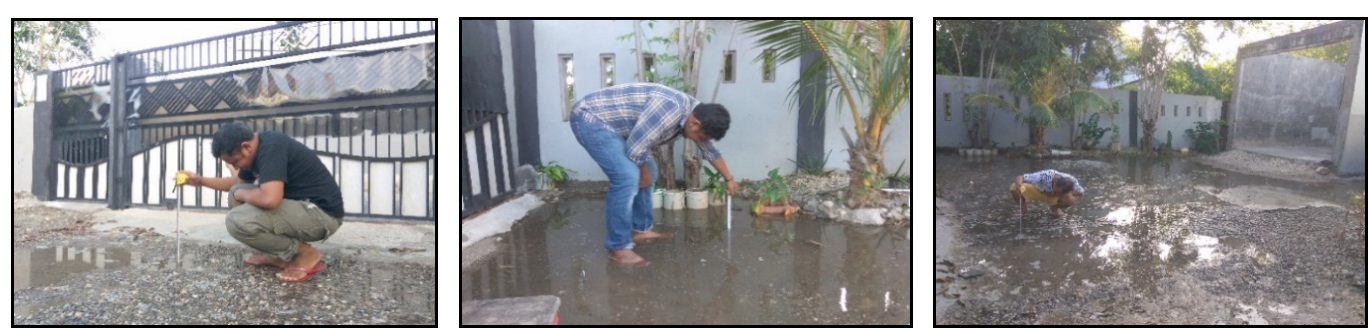

Gambar 2. Pengukuran Penurunan Ketinggian Genangan di Gerbang Akses dan Pojok Halaman

Tabel 3. Penurunan Ketinggian Genangan di Pojok Halaman

\begin{tabular}{|c|c|c|c|c|c|}
\hline \multirow{2}{*}{$\begin{array}{c}\text { Waktu } \\
\text { 5 menit } \\
(\mathrm{X})\end{array}$} & \multicolumn{4}{|c|}{ PENURUNAN KETINGGIAN GENANGAN (Y) DI POJOK HALAMAN (cm) } \\
\cline { 2 - 6 } & $\begin{array}{c}\text { Jumat, } \\
\text { 3 Mei'19 }\end{array}$ & $\begin{array}{c}\text { Sabtu, } \\
4 \text { Mei'19 }\end{array}$ & $\begin{array}{c}\text { Minggu, } \\
\text { 5 Mei'19 }\end{array}$ & $\begin{array}{c}\text { Senin, } \\
\text { 6 Mei'19 }\end{array}$ & $\begin{array}{c}\text { Selasa, } \\
\text { 7 Mei'19 }\end{array}$ \\
\hline $5 "$ & 8.5 & 9.5 & 10.5 & 9.4 & 10.1 \\
\hline $10^{\prime \prime}$ & 7.5 & 8.5 & 9.7 & 8.6 & 9.5 \\
\hline $15 "$ & 6.5 & 7.5 & 8.8 & 8 & 8.9 \\
\hline
\end{tabular}




\begin{tabular}{|c|c|c|c|c|c|}
\hline \multirow{2}{*}{$\begin{array}{l}\text { Waktu } \\
\text { / } 5 \text { menit } \\
\text { (X) }\end{array}$} & \multicolumn{5}{|c|}{ PENURUNAN KETINGGIAN GENANGAN (Y) DI POJOK HALAMAN (cm) } \\
\hline & $\begin{array}{c}\text { Jumat, } \\
3 \text { Mei'19 }\end{array}$ & $\begin{array}{c}\text { Sabtu, } \\
\text { 4 Mei'19 }\end{array}$ & $\begin{array}{l}\text { Minggu, } \\
5 \text { Mei'19 }\end{array}$ & $\begin{array}{c}\text { Senin, } \\
6 \text { Mei'19 }\end{array}$ & $\begin{array}{c}\text { Selasa, } \\
7 \text { Mei'19 }\end{array}$ \\
\hline $20 "$ & 5.6 & 6.8 & 7.9 & 7.2 & 8.3 \\
\hline $25^{\prime \prime}$ & 4.6 & 6.1 & 7.2 & 6.8 & 7.8 \\
\hline $30^{\prime \prime}$ & 3.5 & 5 & 6.4 & 5.8 & 7.4 \\
\hline $35^{\prime \prime}$ & 2.4 & 4.2 & 5.6 & 5.2 & 6.7 \\
\hline $40^{\prime \prime}$ & 1.5 & 3 & 4.8 & 4.5 & 6.1 \\
\hline $45^{\prime \prime}$ & 0.4 & 2.5 & 3.7 & 3 & 5.7 \\
\hline $50^{\prime \prime}$ & & 1.9 & 2.8 & 2.3 & 5.2 \\
\hline $55^{\prime \prime}$ & & 1.2 & 2.3 & 1.7 & 4.7 \\
\hline $60 "$ & & 0.5 & 1.7 & 1.1 & 4.3 \\
\hline $65^{\prime \prime}$ & & & 1.1 & 0.6 & 3.4 \\
\hline $70^{\prime \prime}$ & & & 0.6 & & 2.9 \\
\hline $75^{\prime \prime}$ & & & & & 2.4 \\
\hline $80^{\prime}$ & & & & & 1.8 \\
\hline $85^{\prime \prime}$ & & & & & 1.3 \\
\hline $90^{\prime \prime}$ & & & & & 0.7 \\
\hline
\end{tabular}

Tabel 4. Penurunan Ketinggian di Gerbang Akses

\begin{tabular}{|c|c|c|c|c|c|}
\hline \multirow{2}{*}{$\begin{array}{c}\text { Waktu } \\
\text { / menit } \\
(\mathrm{X})\end{array}$} & \multicolumn{3}{|c|}{ PENURUNAN KETINGGIAN GENANGAN (Y) DI GERBANG AKSES (cm) } \\
\cline { 2 - 6 } & $\begin{array}{c}\text { Jumat, } \\
\text { 3 Mei'19 }\end{array}$ & $\begin{array}{c}\text { Sabtu, } \\
4 \text { Mei'19 }\end{array}$ & $\begin{array}{c}\text { Minggu, } \\
\text { 5 Mei'19 }\end{array}$ & $\begin{array}{c}\text { Senin, } \\
\text { 6 Mei'19 }\end{array}$ & $\begin{array}{c}\text { Selasa, } \\
\text { Mei'19 }\end{array}$ \\
\hline $5 "$ & 5.1 & 5.4 & 4.5 & 4.3 & 4.7 \\
\hline $10^{\prime \prime}$ & 4.5 & 4.8 & 4.2 & 4 & 4.3 \\
\hline $15^{\prime \prime}$ & 4 & 4.3 & 3.9 & 3.7 & 3.9 \\
\hline $20^{\prime \prime}$ & 3.3 & 3.7 & 3.5 & 3.5 & 3.7 \\
\hline $25^{\prime \prime}$ & 2.8 & 3.2 & 3.2 & 3.1 & 3.4 \\
\hline $30^{\prime \prime}$ & 2.2 & 2.7 & 2.7 & 2.7 & 2.9 \\
\hline $35^{\prime \prime}$ & 1.7 & 2.3 & 2.2 & 2 & 2.5 \\
\hline $40^{\prime \prime}$ & 1.3 & 1.8 & 1.7 & 1.7 & 2 \\
\hline $45^{\prime \prime}$ & 0.9 & 1.4 & 1.2 & 1.2 & 1.5 \\
\hline $50^{\prime \prime}$ & 0.5 & 0.9 & 0.7 & 0.7 & 1.1 \\
\hline $55^{\prime \prime}$ & 0.1 & 0.5 & 0.2 & 0.2 & 0.5 \\
\hline $60 "$ & & & & & 0.2 \\
\hline
\end{tabular}

Pola perubahan ketinggian genangan sebagaimana terlihat dalam tabel tersebut menunjukkan bahwa setiap 5 menit, rerata penurunan ketinggian genangan adalah sekitar $0.3 \mathrm{~cm}$. Penurunan terkecil adalah $0.2 \mathrm{~cm}$ dan terbesar $0.7 \mathrm{~cm}$. Penurunan terbesar yaitu $0.7 \mathrm{~cm} / 5$ menit terjadi pada hari pertama eksperimen. Karena uji coba dilakukan pasca musim penghujan, maka besarnya penurunan tersebut diperkirakan terjadi karena kondisi tanah yang kering dan porous. Pola penurunan di 3 hari pertama berbeda dengan di 2 hari terakhir. Hal itu disebabkan karena pola penuangan air di ke-3 hari pertama tersebut dilakukan dengan bantuan mesin sehingga capaian ketinggian muka air genangan terjadi akibat pendeknya durasi penggenangan yaitu selama 17 menit. Di 2 hari terakhir, penggenangan dilakukan 
dengan mengalirkan air secara gravitasi (mesin pompa tidak dihidupkan) sehingga durasi penuangan dan penggenangan lebih panjang yaitu menjadi sekitar 25 menit.

\section{Analisis Regresi Linier Menggunakan Microsoft Excel}

Untuk menganalisis regresi, data diolah menggunakan Microsoft excel dan disajikan secara deskriptif dan tabulasi dari hasil pengukuran di lapangan. Laju infiltrasi ditetapkan dengan menghitung perbandingan penurunan muka air yang mulai konstan dengan waktu pengukuran.

Dimana:

$$
y=a+b x
$$

$\mathrm{a}=$ intercept $; \mathrm{b}=$ slope

Model regresi yang diperoleh untuk ketinggian genangan di pojok halaman adalah:

1) Hari Jumat: $\quad y=5.400+0.212 x$

2) Hari Sabtu: $\quad y=5.600+0.260 x$

3) Hari Minggu: $\quad y=4.450+0.334 x$

4) Hari Senin: $\quad y=6.060+0.128 x$

5) Hari Selasa: $\quad y=7.700+0.103 x$

Tabel 5. Rekapitulasi Peningkatan Ketinggian per 1 Menit untuk Setiap Hari di Pojok Halaman

\begin{tabular}{|c|c|c|c|c|c|}
\hline Hari & $\begin{array}{c}\text { Jumat, } \\
3 \text { Mei'19 }\end{array}$ & $\begin{array}{c}\text { Sabtu, } \\
4 \text { Mei'19 }\end{array}$ & $\begin{array}{c}\text { Minggu, } \\
5 \text { Mei'19 }\end{array}$ & $\begin{array}{c}\text { Senin, } \\
\text { 6 Mei'19 }\end{array}$ & $\begin{array}{c}\text { Selasa, } \\
7 \text { Mei'19 }\end{array}$ \\
\hline Ketinggian Genangan (cm/menit) & 0.212 & 0.260 & 0.334 & 0.128 & 0.103 \\
\hline
\end{tabular}

Nilai dari setiap tabel-tabel dan pola fluktuasi gambar-gambar tersebut secara konsisten menunjukkan trend perubahan dari hari ke hari yang serupa, dan kecenderungan tersebut juga konsisten terjadi untuk tiap pola penggenangan yang berbeda. Hal itu sangat sangat mengindikasikan bahwa peningkatan ketinggian genangan dipengaruhi oleh durasi penggenangan dan/atau intensitas air yang melimpas di atas lahan. Apabila intensitasnya tinggi dan durasi penggenangannya juga lama maka ketinggian genangan yang terjadi merupakan nilai maksimalnya, dan sebaliknya. Namun karena data curah hujan di Kota Kupang menunjukkan bahwa intensitas hujan yang tinggi biasanya terjadi dalam durasi yang singkat, maka debit limpasan yang terjadi di kawasan perkotaan dominan berada dalam level sedang.

Dengan level curah hujan tersebut, seharusnya kawasan perkotaan terbebas dari problem genangan berlebihan. Namun kenyataannya, walaupun durasi hujan relatif singkat, sebagian jalan dan/atau lahan di hilir kawasan perkotaan Kupang seringkali mengalami genangan berlebihan. Hal tersebut dipicu oleh pola drainase konvensional dimana sebagian besar lokasi budidaya dengan segera membuang air limpasan hujan ke luar dari lahan pekarangannya ke hilir kawasan secara gravitasi. Hasil eksperimen dalam studi ini sangat mengindikasikan bahwa apabila di setiap kapling budidaya tersedia cukup lahan terbuka yang digunakan sebagai area resapan maka tidak terjadi limpasan air ke luar kapling dimaksud (zero run-off) sehingga penggenangan berlebihan di hilir kawasan dapat dihilangkan dan/atau diminimalkan. 


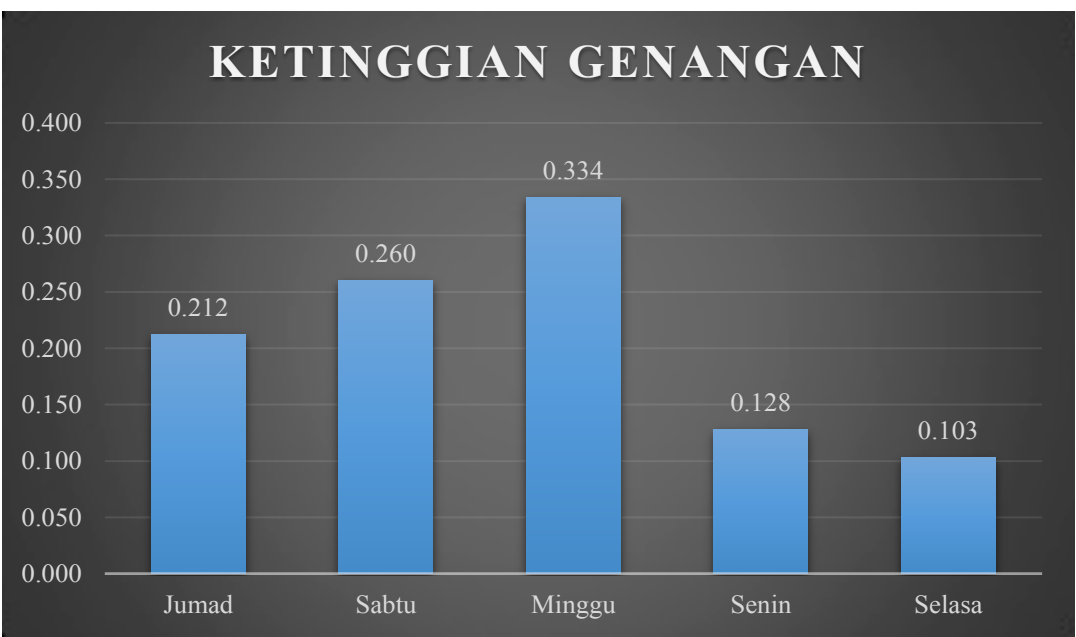

Gambar 3. Peningkatan Ketinggian Genangan per 1 Menit untuk Setiap Hari di Pojok Halaman

Berdasarkan hasil perhitungan regresi linear menggunakan Microsoft excel untuk hari Jumad 3 Mei 2019, nilai ketinggian genangan yang diperoleh adalah $0.212 \mathrm{~cm} / \mathrm{menit}$. Hal ini menunjukkan bahwa, apabila waktu bertambah 1 menit, maka ketinggian genangan dapat meningkat sebesar $0.212 \mathrm{~cm}$. Sedangkan, untuk hari Sabtu 4 Mei 2019, ketinggian genangan dalam 1 menit adalah sebesar $0.260 \mathrm{~cm}$. Hari Minggu 5 Mei 2019, ketinggian genangan dalam 1 menit adalah sebesar $0.334 \mathrm{~cm}$. Hari Senin 6 Mei 2019, ketinggian genangan dalam 1 menit adalah sebesar $0.128 \mathrm{~cm}$. Dan hari Selasa 7 Mei 2019, ketinggian genangan dalam 1 menit adalah sebesar $0.103 \mathrm{~cm}$.

Model regresi yang diperoleh untuk ketinggian genangan di gerbang akses adalah:

1) Hari Jumat: $\quad y=3.400+0.212 x$

2) Hari Sabtu: $\quad y=3.700+0.254 x$

3) Hari Minggu: $\quad y=2.550+0.328 x$

4) Hari Senin: $\quad y=3.780+0.170 x$

5) Hari Selasa: $\quad y=5.640+0.115 x$

Dengan demikian jika perhitungan regresi linear menggunakan Microsoft Excel tersebut direkapitulasi, maka nilai slope yang diperoleh adalah seperti yang ditunjukan pada Tabel 6 dan Gambar 4 di bawah ini:

Tabel 6. Rekapitulasi Peningkatan Ketinggian per 1 Menit untuk Setiap Hari di Gerbang Akses

\begin{tabular}{|c|c|c|c|c|c|}
\hline Hari & $\begin{array}{c}\text { Jumat, } \\
\text { 3 Mei'19 }\end{array}$ & $\begin{array}{c}\text { Sabtu, } \\
4 \mathrm{Mei}^{\prime} 19\end{array}$ & $\begin{array}{c}\text { Minggu, } \\
5 \mathrm{Mei} 19\end{array}$ & $\begin{array}{c}\text { Senin, } \\
\text { 6 Mei'19 }\end{array}$ & $\begin{array}{c}\text { Selasa, } \\
7 \text { Mei'19 }\end{array}$ \\
\hline Ketinggian Genangan (cm/menit) & 0.212 & 0.254 & 0.328 & 0.170 & 0.115 \\
\hline
\end{tabular}




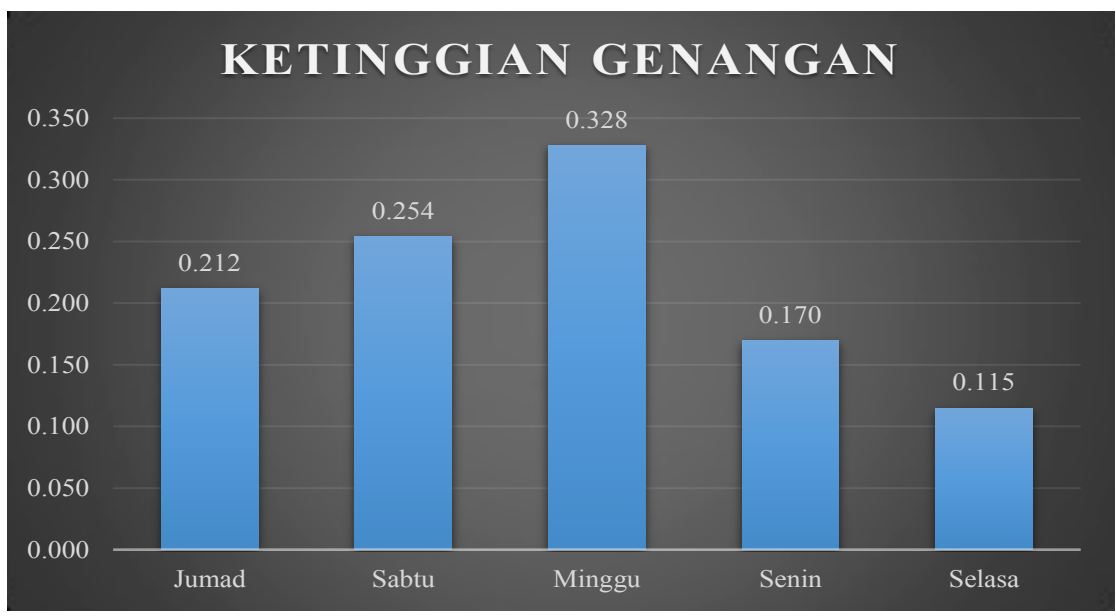

Gambar 4. Peningkatan Ketinggian Genangan per 1 Menit untuk Setiap Hari di Gerbang Akses

Berdasarkan hasil perhitungan regresi linear menggunakan Microsoft excel untuk hari Jumad 3 Mei 2019, nilai ketinggian genangan yang diperoleh adalah $0.212 \mathrm{~cm} / \mathrm{menit}$. Hal ini menunjukkan bahwa, apabila waktu bertambah 1 menit, maka ketinggian genangan dapat meningkat sebesar $0.212 \mathrm{~cm}$. Sedangkan, untuk hari Sabtu 4 Mei 2019, ketinggian genangan dalam 1 menit adalah sebesar $0.254 \mathrm{~cm}$. Hari Minggu 5 Mei 2019, ketinggian genangan dalam 1 menit adalah sebesar $0.328 \mathrm{~cm}$.. Hari Senin 6 Mei 2019, ketinggian genangan dalam 1 menit adalah sebesar $0.170 \mathrm{~cm}$. Dan hari Selasa 7 Mei 2019, ketinggian genangan dalam 1 menit adalah sebesar $0.115 \mathrm{~cm}$.

Model regresi yang diperoleh untuk penurunan ketinggian genangan di pojok halaman adalah:

1) Hari Jumat: $\quad y=9.558-0.202 x$

2) Hari Sabtu: $\quad y=10.077-0.165 x$

3) Hari Minggu: $\quad y=11.111-0.157 x$

4) Hari Senin: $\quad y=10.288-0.153 x$

5) Hari Selasa: $\quad y=10.584-0.109 x$

Dengan demikian jika perhitungan regresi linear menggunakan Microsoft Excel tersebut direkapitulasi, maka nilai slope yang diperoleh adalah seperti yang ditunjukan pada Tabel 7 dan Gambar 5 di bawah ini:

Tabel 7. Rekapitulasi Penurunan Ketinggian per 1 Menit untuk Setiap Hari di Pojok Halaman

\begin{tabular}{|c|c|c|c|c|c|}
\hline Hari & $\begin{array}{c}\text { Jumat, } \\
\text { 3 Mei'19 }\end{array}$ & $\begin{array}{c}\text { Sabtu, } \\
4 \text { Mei'19 }\end{array}$ & $\begin{array}{c}\text { Minggu, } \\
5 \text { Mei'19 }\end{array}$ & $\begin{array}{c}\text { Senin, } \\
6 \text { Mei'19 }\end{array}$ & $\begin{array}{c}\text { Selasa, } \\
7 \text { Mei'19 }\end{array}$ \\
\hline Penurunan Genangan (cm/menit) & 0.202 & 0.165 & 0.157 & 0.153 & 0.109 \\
\hline
\end{tabular}




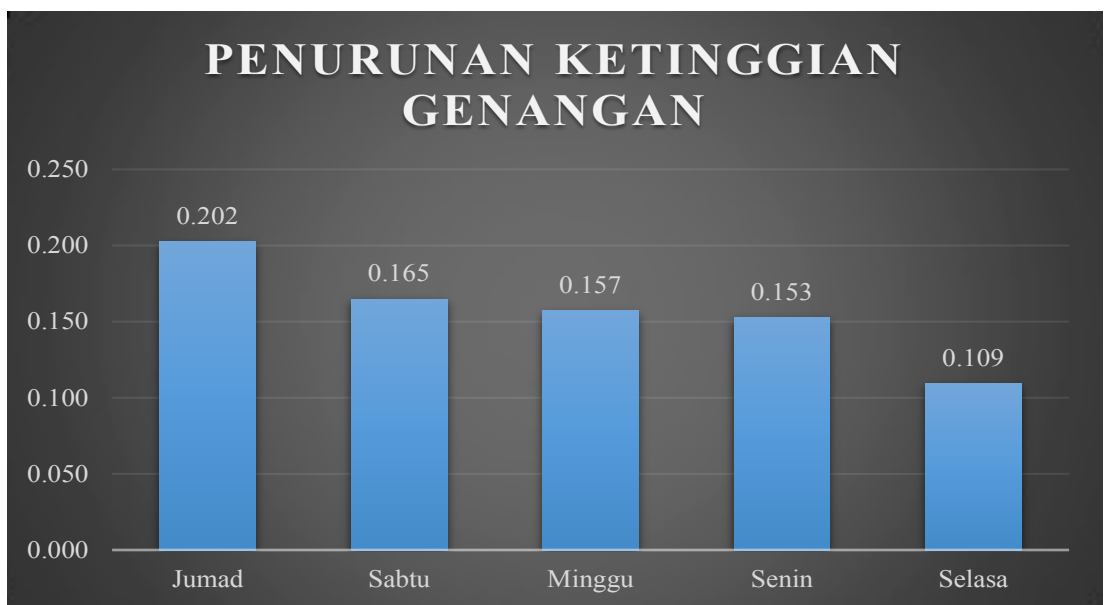

Gambar 5. Penurunan Ketinggian Genangan per 1 Menit untuk Setiap Hari di Pojok Halaman

Berdasarkan hasil perhitungan regresi linear menggunakan Microsoft excel untuk hari Jumad 3 Mei 2019, nilai penurunan ketinggian genangan yang diperoleh adalah $0.202 \mathrm{~cm} / \mathrm{menit}$. Hal ini menunjukkan bahwa, apabila waktu bertambah 1 menit, maka penurunan ketinggian genangan yang terjadi adalah sebesar $0.212 \mathrm{~cm}$. Sedangkan, untuk hari Sabtu 4 Mei 2019, penurunan ketinggian genangan dalam 1 menit adalah sebesar $0.165 \mathrm{~cm}$. Hari Minggu 5 Mei 2019, penurunan ketinggian genangan dalam 1 menit adalah sebesar $0.157 \mathrm{~cm}$. Hari Senin 6 Mei 2019, penurunan ketinggian genangan dalam 1 menit adalah sebesar $0.153 \mathrm{~cm}$. Dan hari Selasa 7 Mei 2019, penurunan ketinggian genangan dalam 1 menit adalah sebesar $0.109 \mathrm{~cm}$.

Model regresi yang diperoleh untuk penurunan ketinggian genangan di gerbang akses adalah:

1) Hari Jumat: $y=5.422-0.101 x$

2) Hari Sabtu: $y=5.736-0.097 x$

3) Hari Minggu: $y=5.175-0.088 x$

4) Hari Senin: $y=4.967-0.083 x$

5) Hari Selasa: $y=5.261-0.083 x$

Dengan demikian jika perhitungan regresi linear menggunakan Microsoft Excel tersebut direkapitulasi, maka nilai slope yang diperoleh adalah seperti yang ditunjukan pada Tabel 8 dan Gambar 6 dibawah ini:

Tabel 8. Rekapitulasi Penurunan Ketinggian per 1 Menit untuk Setiap Hari di Gerbang Akses

\begin{tabular}{|c|c|c|c|c|c|}
\hline Hari & $\begin{array}{c}\text { Jumat, } \\
3 \text { Mei'19 }\end{array}$ & $\begin{array}{c}\text { Sabtu, } \\
\text { 4 Mei'19 }\end{array}$ & $\begin{array}{l}\text { Minggu, } \\
5 \text { Mei'19 }\end{array}$ & $\begin{array}{c}\text { Senin, } \\
6 \text { Mei'19 }^{2}\end{array}$ & $\begin{array}{c}\text { Selasa, } \\
7 \text { Mei'19 }\end{array}$ \\
\hline Penurunan Genangan $(\mathrm{cm} /$ menit$)$ & 0.101 & 0.097 & 0.088 & 0.083 & 0.083 \\
\hline
\end{tabular}




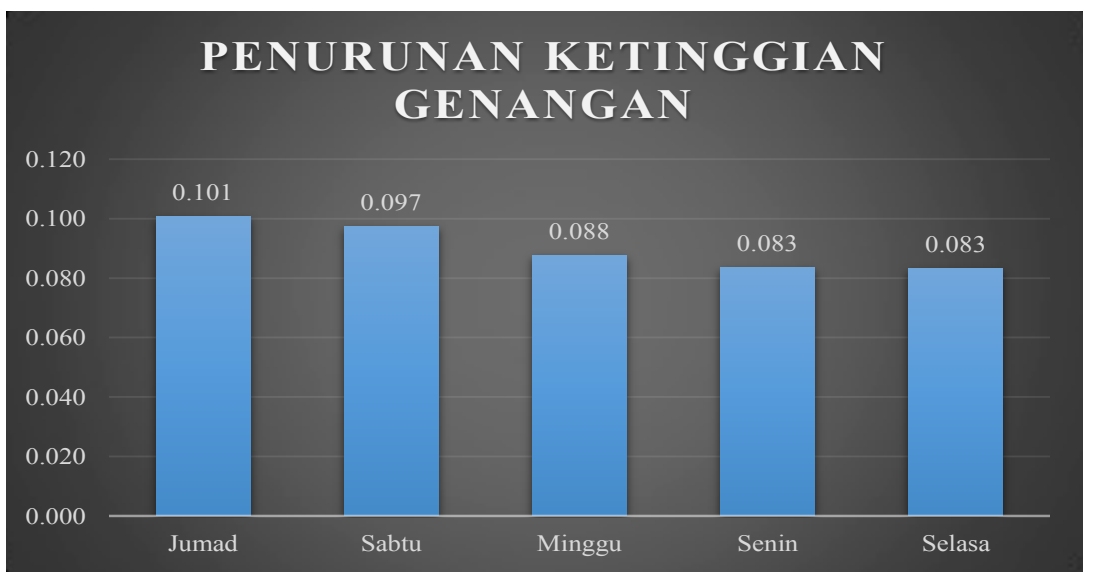

Gambar 6. Penurunan Ketinggian Genangan per 1 Menit untuk Setiap Hari di Gerbang Akses

Berdasarkan hasil perhitungan regresi linear menggunakan Microsoft excel untuk hari Jumad 3 Mei 2019, nilai penurunan ketinggian genangan yang diperoleh adalah $0.101 \mathrm{~cm} / \mathrm{menit}$. Hal ini menunjukkan bahwa, apabila waktu bertambah 1 menit, maka penurunan ketinggian genangan yang terjadi adalah sebesar $0.101 \mathrm{~cm}$. Sedangkan, untuk hari Sabtu 4 Mei 2019, penurunan ketinggian genangan dalam 1 menit adalah sebesar $0.097 \mathrm{~cm}$. Hari Minggu 5 Mei 2019, penurunan ketinggian genangan dalam 1 menit adalah sebesar $0.088 \mathrm{~cm}$. Hari Senin 6 Mei 2019, penurunan ketinggian genangan dalam 1 menit adalah sebesar $0.083 \mathrm{~cm}$. Dan hari Selasa 7 Mei 2019, penurunan ketinggian genangan dalam 1 menit adalah sebesar $0.083 \mathrm{~cm}$.

Dari keseluruhan data laju infiltrasi tersebut terindikasi kuat bahwa kemampuan tanah dalam meresapkan air dengan intensitas dan/atau debit yang diujicobakan adalah tergolong sangat tinggi karena setelah 5 hari penggenangan air tetap dapat diresapkan dengan kecepatan atau laju infiltrasi yang relatif konstan. Hal ini mendorong dilakukannya studi lebih jauh tentang potensi konservasi lahan dan/atau air. Konservasi lahan dimungkinkan karena dengan ketinggian genangan dan/atau debit air yang diresapkan tersebut, kandungan air dalam lapisan permukaan tanah memungkinkan keberlanjutan kelembaban tanah yang sangat dibutuhkan untuk penanaman dan pertumbuhan tanaman. Lebih jauh, dengan tingkat porositas tersebut peluang terjadinya imbuhan air tanah (perkolasi) perlu diteliti lebih jauh sehingga dapat dijadikan dasar pengelolaan sumber daya air secara berkelanjutan.

\section{Kesimpulan}

Kesimpulan yang dapat dibuat dari hasil analisis dan pembahasan tersebut di atas adalah:

- Laju penurunan ketinggian genangan air dipengaruhi oleh jenis kegiatan di atas lahan dimana bagian tanah yang sering dilintasi kendaraan dan/atau pejalan kaki bersifat lebih kedap air dari pada bagian lahan yang jarang dilintasi.

- Walaupun perbedaan laju penurunan (infiltrasi) air hanya sekitar 2-3 cm / 5 menit namun hal itu mengindikaskan bahwa ketersediaan area terbuka tetap diperlukan untuk mendukung implementasi model zero run-off di kawasan terbangun perkotaan. Implikasinya, direkomendasikan agar setiap kapling budidaya harus menyediakan area terbuka untuk fungsi resapan air hujan.

\section{Daftar Pustaka}

Hakim, N. dkk. (1986). Dasar-dasar ilmu tanah. Universitas Lampung. Lampung, 488

Kurnia, dkk. (2004). Sifat Fisik Tanah dan Metode Analisisnya 
Putra, A.E. dkk. (2013). Kajian Laju Infiltrasi Tanah Pada Berbagai Penggunaan Lahan Di Desa Tongkoh Kecamatan Dolat Rayat Kabupaten Karo (hlm. 38). Universitas Lampung: Lampung.

Maria, R., \& Lestiana, H. (2014). Pengaruh Penggunaan Lahan Terhadap Fungsi Konservasi AirTanah di Sub Das Cikapundung. Riset Geologi dan Pertambangan, 24(2), 77-89

Muharomah, R., \& Putranto, D.D.A. (2014). Analisis Run-Off Sebagai Dampak Perubahan Lahan Sekitar Pembangunan Underpass Simpang Patal Palembang Dengan Memanfaatkan Teknik GIS. Jurnal Teknik Sipil dan Lingkungan, 2(3)

Wardhana, I.K.W. (2015). Prediksi Hujan Untuk Wilayah Kota Kupang Dengan Metode Data Mining Pohon Keputusan C4.5. Jurnal Sekolah Tinggi Meteorologi Klimatologi dan Geofisika

Wardiha, dkk. (2013). Pemetaan Permasalahan Penyediaan Air Minum di Provinsi Nusa Tenggara Timur Dengan System Interrelationship Model. Lingkungan Tropis, 6(2), 105-119

Utaya, S. (2008). Pengaruh Perubahan Penggunaan Lahan Terhadap Sifat Biofisik Tanah dan Kapasitas Infiltrasi di Kota Malang. FMIPA Geografi, 22(2), 99-112 